https://doi.org/10.48009/1_iis_2006_124-128

\title{
AN ACTIVE LEARNING PEDAGOGY IN A PROGRAMMING COURSE
}

\author{
Corrine Brown, Ohio University, brownc@ohio.edu
}

\begin{abstract}
The use of technology makes it possible to accommodate different learning styles in providing course materials. Course designs that "meet the student's goal, learning style, pace and life situation will pay off handsomely in increased learning" [6, p. 202]. There is an abundant amount of literature on learning styles, but how do you incorporate different learning styles and still cover the required material in a course? This paper describes a pedagogy using customized rich media presentations as a key component in a beginning programming course. The impact of rich media presentations is measured by student evaluations before and after their introduction in the course.
\end{abstract}

Keywords: Learning Styles, Pedagogy, Programming, VB.NET

\section{INTRODUCTION}

Today's students are the "web generation" and their expectations are different than past generations [5]. Current hardware and software offers the possibility to create new learning opportunities but does not "guarantee effective learning" [1]. But many of us that teach students the discipline of technology do not use that same technology to engage students and enhance learning opportunities. The National Survey of Student Engagement found that "in institutions where faculty members use effective educational practices more frequently in their classes, students are more engaged overall and gain more from college" [9, p. 14].

How much students learn is influenced by "the student's attributes as a learner and the instructor's teaching style" [4]. Unfortunately, students' learning styles often do not match the teaching style of their professors. While it is not feasible to design a course that integrates unique learning plans for each student in a large class, it is possible to incorporate many different learning activities in a course. When learning activities are designed to correspond with different learning styles, students are able to experience at least some learning activities that match their learning style. In a longitudinal study of engineering education, Richard Felder at North Carolina State University reported that "teaching to the full spectrum of learning styles improves students' learning, satisfaction with their instruction, and self-confidence" [3, p. 18].

\section{LITERATURE REVIEW}

As discussed above, engaging students is an important step in the learning process. Marzano [2001] describes a taxonomy of educational objectives which begins with "the self-system" [7]. In the self-system, the student makes a decision to engage in a learning activity or continue with some other activity. Current hardware and software enables the distribution of information, allowing students to engage in a learning activity at any time. Marzano states that "the self-system is engaged first, then the metacognitive system, and finally the cognitive system" [7, p. 11]. The knowledge base and previous experiences of students will influence their decision to engage in a learning activity.

Models of experiential learning "suggest the idea that learning is by its very nature a tension and conflictfilled process" [6, p. 30]. One of our goals as educators should be to decrease the tension that is inherent in the learning process. David Kolb suggests that prior experiences influence how we learn. The Kolb model outlines four basic learning modes and four learning styles. The four learning modes are as follows:

- "An orientation toward concrete experience focuses on being involved in experiences and dealing with immediate human situations in a personal way" [6, p.. 68]. Students who prefer concrete experience prefer to apply skills with the teacher as a coach or helper [6].

- "An orientation toward reflective observation focuses on understanding the meaning of ideas and situations by carefully observing and impartially describing them" [6, p. 68]. Students preferring reflective observation are helped when the teacher provides expert interpretation [6].

- "An orientation toward abstract conceptualization focuses on using logic, ideas, and concepts" [6, p. 69]. Those learners who prefer abstract conceptualization are helped by case studies and theoretical readings [6].

- "An orientation toward active experimentation focuses on actively influencing people and changing situations" $[6, \quad$ p. 69]. Active 
Experimental learners are helped when activities include projects, homework problems and the application of skills to real-life problems [6].

The four basic learning styles are combinations of the above learning modes. The learning styles are as follows:

- Convergent, which is a combination of abstract conceptualization and active experimentation. A person with this learning style does well with "problem solving, decision making and the practical application of ideas" [6, p. 77].

- Divergent, a learning style combining the concrete experience and reflective observation modes. The divergent style emphasizes "adaptation by observation rather than action" $[6$, p. 78].

- Assimilation, a combination of abstract conceptualization and reflective observation. The assimilation learning style emphasizes "ideas and abstract concepts" [6, p. 78].

- Accommodative, which combines the modes of concrete experience and active experimentation. The accommodation style suits those who like to do things and get involved in new experiences [6].

The following case study will describe the process used in one MIS course to incorporate various learning styles into the course and to introduce rich media presentations for an accommodative learning activity outside the classroom.

\section{PEDAGOGY}

\section{Original Pedagogy}

Dr. Raymond Frost, professor of MIS at Ohio University, developed a pedagogical technique to be used in an introductory core requirement MIS course. Faculty members in the MIS department at Ohio University have agreed to adopt the pedagogy for all introductory MIS courses. The adopted pedagogy, which is represented below, fits well with Kolb's model of experiential learning.

- Level 0: Relate concept to real world application

- Level 1: Hands-on, step-by-step assignment

- Level 2: Best practice-copy a design

- Level 3: Apply concepts to a new situation

The beginning programming course follows the four stage pedagogy. The first programming course in the curriculum uses VB.NET in the ASP.NET 2.0 environment. Using Microsoft's Visual Web
Developer, students develop interactive web pages while covering the basic programming constructs that are typically found in beginning programming courses. In Level 0, the learning activities correlate with Kolb's divergent learning style. Concepts are introduced using printed and online materials with a concentration on examples that students may have experienced. For example, when introducing master pages, web sites that employ the master page concept are displayed and discussed in class. Students are then asked to find other web sites using the same concept. Selected students then share what they have found with the class and explain why the web site they have chosen fits the criteria.

Once master pages have been seen in action, students move to Level 1. Level 1 learning activities use techniques which correspond to Kolb's accommodative learning style. Students follow detailed step by step directions to create their own master page for one of three different websites developed over the term. The Level 1 directions were originally made available to students as a word document, with diagrams and written step-by-step procedures. Using the written material as a reference, the Level 1 assignment was completed during a class period, following an instructor led presentation of the material. Problems encountered during the hands-on in class activity included the following:

1. Students were not familiar with the Integrated Development Environment (IDE) and had difficulty moving between screens

2. Students would get behind trying to duplicate the instructor's presentation

3. Students would encounter an error that could not be easily corrected causing a delay for others in the class while the instructor or an assistant worked with the student

4. Students were so busy copying the instructor's presentation, they missed the conceptual explanation

5. Student absences increased as the material became more complex

6. Students who missed class did not have the previous meeting's material completed at the next class meeting, causing delays since each presentation built on the previous one.

The Level 2 learning activities included readings and instructions which were appropriate for learners that prefer the assimilation learning style. The Level 2 activities were presented to students in printed form, both in PowerPoint with notes added and in a word document which included the PowerPoint slides and lecture notes. Material was covered in class and then 
students were to complete exercises and activities that were included in the printed materials on their own.

The Level 3 assignment described a business scenario; the students developed the web pages and applications needed to solve the business problem. The Level 3 assignment included activities for the convergent learner. Two examples of business scenarios used as Level 3 assignments were online retail stores and online reservation systems. Students were familiar with both of these types of applications and could relate the requirements of the assignments to their real life experiences.

\section{Pedagogy Modified with Rich Media}

Using Microsoft Producer, the Level 1 activities were moved to a rich media presentation environment. Screen capture videos were produced and made available to students from the course web site. The rich media presentations could be watched by students anywhere at any time. There are many screen capture programs available, but Microsoft Producer was chosen because it was a free download [8] and there was a short learning curve needed to develop materials. Since the course material covers the development of web applications rather than Windows applications, there were virtually no instruction materials available from traditional book publishers for VB.NET at the beginning programming course level; therefore, it was necessary to develop customized materials. Using the screen capture tool in MS Producer, the instructor developed an application and explained the concepts being used. The media presentation was customized to address a given business scenario covering design issues, programming constructs, and logic in a visual and oral step-by-step process. The students were required to watch the media presentation and produce the same application before coming to class. Students could watch at any time that was convenient for them and it was not uncommon to see time stamps of 1 a.m. to 4 a.m. for assignments posted to the student server. Students watched the rich media presentation on their schedule, when they decided to become engaged in learning, not in a time frame imposed by the registrar. Presentations could be stopped, paused, or advanced, offering opportunities to cover concepts and material as many times as necessary.

Level 2 learning activities were completed in class following instructor and student led presentations. Level 2 activities applied the concepts covered in the Level 1 rich media presentation. Unlike the experience of conducting the Level 1 activities in class, very few problems were encountered with the
Level 2 in-class activities. Class presentations went more smoothly since students had experience with the IDE and had already developed an application using the concepts and constructs being reviewed in class. Students that encountered problems were able to correct the problem with minimal intervention. Student absences were almost non-existent. Even as material became more difficult, students attended and participated in the classroom activities. The types of questions asked in class changed as well. Instead of asking questions about "how to do something" questions became more of the "what would be the effect" variety. Student questions reflected a deeper understanding of the material rather than "show me how" mentality, they were concerned about the effect of the design on customers and how the code could be improved.

Level 3 assignments remained the same, with students designing and developing a website for an assigned business scenario.

\section{RESULTS}

The following data show the results from two courses with the same instructor, common written notes, assignments and assessments. The differences between the courses were moving the Level 1 stepby-step learning activity from a combination of printed materials and lecture presentation to a rich media presentation and moving the Level 2 activity from an out-of-class to an in-class activity. The student evaluations are measured on a five point Likert scale as shown:

$$
\begin{aligned}
& 1=\text { Strongly disagree } \\
& 2=\text { Agree } \\
& 3=\text { Neutral } \\
& 4=\text { Agree } \\
& 5=\text { Strongly agree. }
\end{aligned}
$$

The results of student evaluations from courses before and after the introduction of rich media presentations are shown below. 

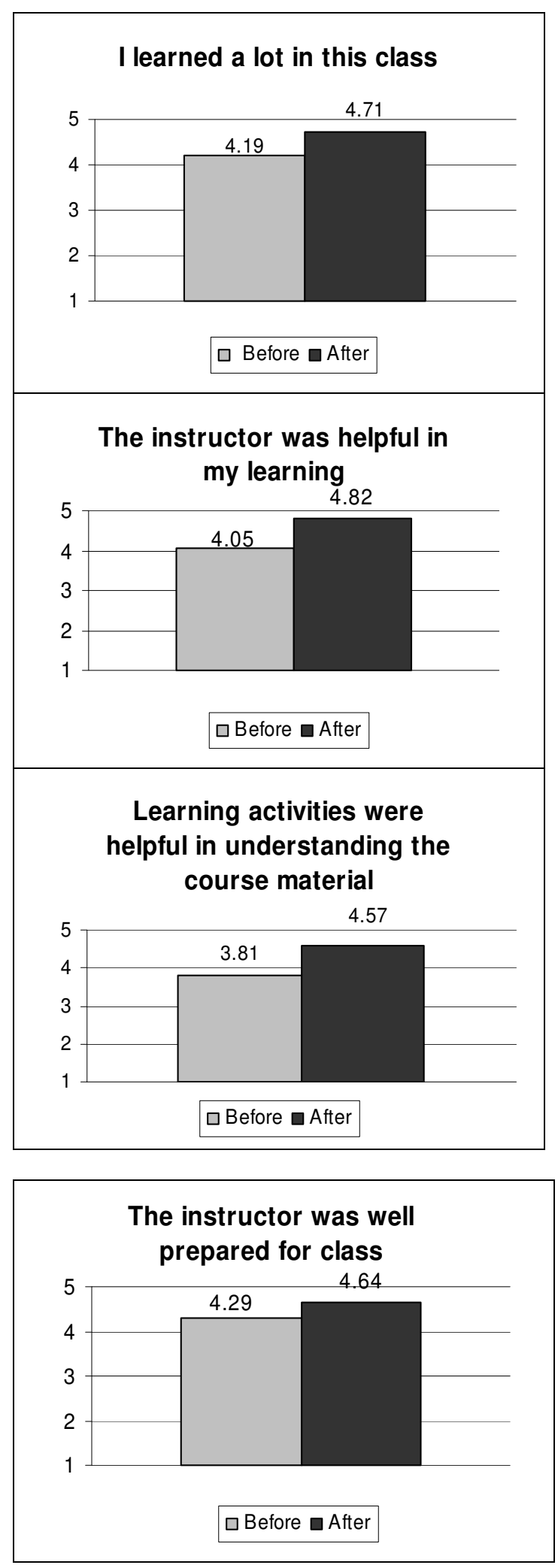

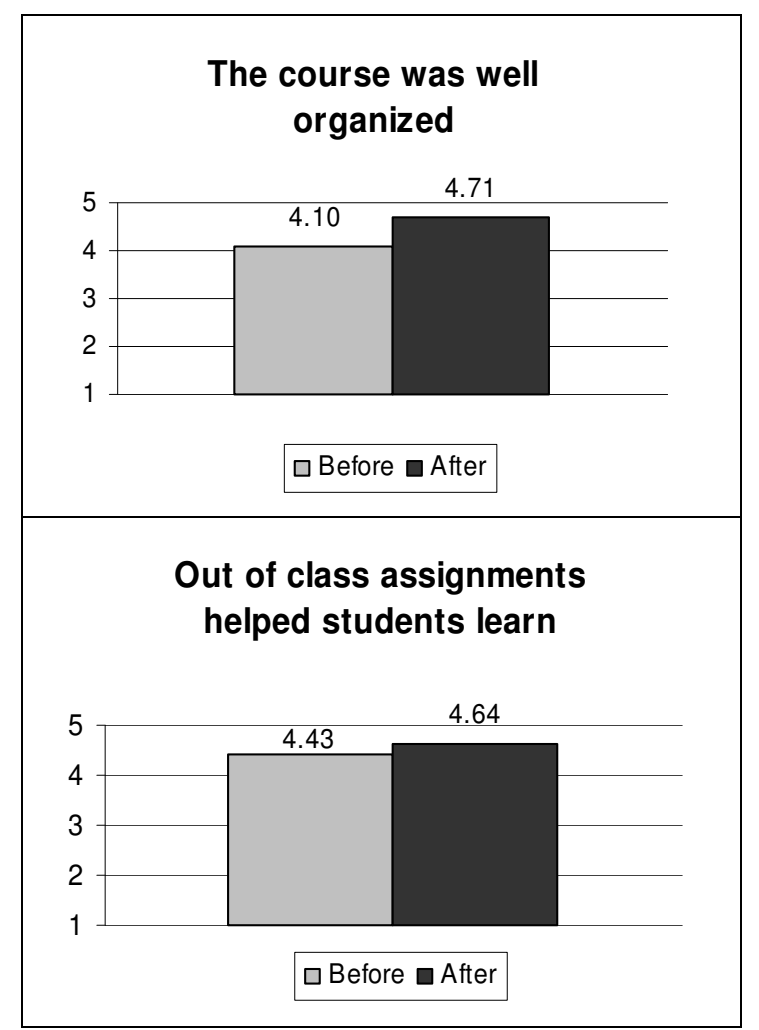

Figure 1. Before/after Student Evaluations

\section{SUMMARY}

The value added by moving the Level 1 learning activity to a rich media presentation is supported by the results of the student evaluations and enhanced classroom activities. Student evaluations reflect increases in perceived usefulness of learning activities, in the amount students learned, the helpfulness and preparation of the instructor, as well as the organization of the class. Student questions reflect a deeper understanding of material, student attendance increased, and fewer errors were encountered during in class exercises. The introduction of rich media presentations generated higher perceived learning and usefulness of the learning activities.

\section{REFERENCES}

1. Bransford, J.D., Brown, A.L., \& Cocking, R.R., eds. (2000). How People Learn: Brain, Mind, Experience, and School. Washington, D.C.: National Academy Press.

2. Felder, R. M. (1996). Matters of Style. ASEE Prism, 6(4), 18-23. Available online at http://www.ncsu.edu/felder-public/Papers/LS-

Prism.htm 
3. Felder, R. M. \& Brent, R. (2005). Understanding Student Differences. Journal of Engineering Education, 94(2), 57-72

4. Chapman, A. (1995-2006). Based on the original concept of David Kolb. From the free resources website

http://www.businessballs.com/kolblearningstyles .htm

5. Johnstone, S.M., Ewell, P. \& Paulson, K. (2002). Student Learning as Academic Currency. American Council on Education Center for Policy Analysis. Available online at http://www.acenet.edu/bookstore/pdf/distributedlearning/distributed-learning-04.pdf

6. Kolb, D. A. (1984). Experiential Learning: Experience as the Source of Learning and Development. Englewood Cliffs, NJ: PrenticeHall, Inc.
7. Marzano, R. J. (2001). Designing a New Taxonomy of Educational Objectives. Thousand Oaks, CA: Corwin Press, Inc.

8. Microsoft. [online], Available http://www.microsoft.com/downloads/details.asp $\mathrm{x}$ ?FamilyID=1b3c76d5-fc75-4f99-94bc784919468e73\&DisplayLang=en

9. National Survey of Student Engagement (2005). The NSSE 2005 Report: Exploring Different Dimensions of Student Engagement. Bloomington, IN. Indiana University Center for Post-secondary Research and Planning. Available online at http://nsse.iub.edu/pdf/NSSE2005_annual_report .pdf 